\title{
The acquisition of trace supraordinate stimulus control in pigeons
}

\author{
EDWARD F. MEEHAN \\ College of Staten Island of the City University of New York, New York, New York 10301
}

\begin{abstract}
Match-to-sample and oddity-from-sample problems with four colors were acquired by two pigeons under the supraordinate control of a line tilt superimposed on samples. Since the supraordinate stimulus terminated before the comparison stimuli were presented, accurate matching and oddity performance indicated trace stimulus control as well. The temporal extent of trace control was assessed in one subject by presenting probes-trials without a line tilt on the sample-in which the basis of correct responding was the supraordinate stimulus presented on the previous trial. Trace supraordinate control did not extend between trials. Subsequently, the delay between the termination of the supraordinate stimulus and the presentation of the comparison stimuli was gradually increased within a trial. Both subjects were able to perform matching and oddity over longer delays, and eventually on probe trials, although accuracy decreased. Results were discussed in terms of instructional stimulus control and memory.
\end{abstract}

Instructional stimuli have two general properties: (1) to control responding over a range of discrimination problems, that is, to exert supraordinate control (Reynolds, 1968) and (2) to continue to exert control beyond the stimulus duration, which is called trace control. Stimuli in match-to-sample and oddity-fromsample procedures combine elements of both properties and permit the investigation of instructional stimulus control (Cumming \& Berryman, 1961).

Supraordinate control or higher order conditional stimulus control (Nevin, 1973) deals with classes of stimulus-response relationships. Matching can serve as a class of stimulus-response relationships, indicating supraordinate control over a range of problems, e.g., matching colors. Supraordinate stimulus control was studied by Nevin and Liebold (1966), who trained pigeons to perform match-to-sample using red and green stimuli when a yellow light above the response keys was illuminated and to perform oddity-from-sample when it was off. The yellow light exerted supraordinate control over problems when the center key was either red or green. If a stimulus terminates before the opportunity to respond, then the procedure involves trace stimulus control. Delayed match-to-sample (Blough, 1959) examines the trace aspect of the sample's control by delaying the onset of the comparison stimuli until after the termination of the sample. If the sample continues to exert control beyond its duration, then trace stimulus control is indicated.

Reprints may be obtained from the author at the Department of Psychology, College of Staten Island, CUNY, 130 Stuyvesant Place, Staten Island, New York 10301. This research was supported in part by the Research Foundation of The City University of New York, Grant RF 11541. The author would like to thank Dr. Lanny Fields for his help on the manuscript
The present study investigated the acquisition of instructional stimulus control in pigeons. This was accomplished by establishing a supraordinate stimulus dimension that controlled matching and oddity but which was not present during the choice of comparison (0-sec delay). An attempt was made to modify the extent of the trace control by titrating the delay interval between the offset of the supraordinate stimulus and the opportunity to respond to the comparison stimuli. Further, if the trace aspect of instructional control extended beyond one trial, i.e., exerted control over more than one problem, then the stimulus would serve as an instruction to select either the matching comparison or the nonmatching comparison. The trace aspect, therefore, was examined both within and between trials.

\section{METHOD}

\section{Subjects \\ Two naive White Carneaux pigeons, about 2 years old at the start of the study, were maintained at $80 \%$ of ad-lib weight. Sessions were conducted 5 days a week.

\begin{abstract}
Apparatus
A Scientific Prototype chamber (Model B-400) was housed in a sound-attenuated enclosure. One wall of the chamber contained three $2.5-\mathrm{cm}$ clear plastic keys in a horizontal line set $8.25 \mathrm{~cm}$ apart and $24.1 \mathrm{~cm}$ from the floor. A feeder was located $14.0 \mathrm{~cm}$ below the center key. Visual stimuli were projected on the keys by IEE in-ine display units (Model 10-6777-441). Red, green, blue, yellow, and white fields as well as white line tilts of $0^{\circ}$ and $90^{\circ}$ could be projected on each key. Response key depression required a force exceeding $.2 \mathrm{~N}$. Reinforcement consisted of 3-sec access to mixed grain. White noise was present during the sessions. No houselight was used.

Procedure

Preliminary training consisted of first shaping keypecks at a
\end{abstract} white center key, which terminated the center-key illumination}


and illuminated one side key with white light. The pigeons were then trained to peck the white side key, which produced reinforcement. All preliminary training was completed with white key lights. Each trial began with a lit center key and terminated with reinforcement after a response to the lit side key. There was a $2-\mathrm{sec}$ intertrial interval. After 100 trials, the response requirement to the center key was increased to a fixed ratio 40 (FR 40). This was accomplished by increasing the FR value by five responses after each 60 -trial session until the FR 40 requirement was met, unless there was ratio strain. The pigeons then performed 10 sessions under the FR $\mathbf{4 0}$ requirement. The position of the lit side key was counterbalanced. Responses to dark keys had no consequence.

Training on the oddity-from-sample task began with two colors, red and green. It was a standard 0 -sec delay procedure, with an FR 40 observing response requirement. Each trial began with the sample illuminated on the center key. Forty responses to the center key terminated the center-key light and turned on the side-key lights. A response to the side key that was different from the sample produced reinforcement. A response to the side key that was the same as the sample produced a 3.0-sec blackout. A $90^{\circ}$ white line was superimposed on each sample during oddity training. Color and position of the correct side key were counterbalanced.

Upon reaching the criterion of $85 \%$ correct for five consecutive sessions, blue-yellow trials of oddity-from-sample were substituted for one half of the red-green trials. The $90^{\circ}$ line tilt appeared on each blue or yellow sample. When pigeons had performed for five consecutive sessions with $85 \%$ accuracy on the red-green, blue-yellow oddity task, then match-to-sample trials, with a $0^{\circ}$ line tilt superimposed on the sample were substituted on onehalf of the trials. One-half of the match trials were red-green, one-half blue-yellow. Match-to-sample trials were the same as oddity trials, except for the line tilt present on the sample and the contingencies of reinforcement. In match-to-sample, a response to the side key that was the same as the sample produced reinforcement. A response to the side key that was different from the sample produced the blackout. Therefore, a trial with the $0^{\circ}$ line on a red sample indicated match-to-sample and the red comparison was the correct alternative, while the $90^{\circ}$ line on a red sample indicated oddity-from-sample and the green comparison was the correct alternative.

Sessions were increased to 120 trials, 60 of oddity and 60 of matching. Center-key color and position of correct alternatives were counterbalanced over a 60 -trial sequence for both matching and oddity tasks. The sequence was repeated twice for each session. The criterion for supraordinate stimulus control was 10 consecutive sessions at $85 \%$ correct. After 100 sessions, the blackout produced by errors was increased to $10 \mathrm{sec}$. The intertrial interval remained at $2.0 \mathrm{sec}$.

To assess the extent of the supraordinate control, one pigeon (No. 36) was given 30120 -trial sessions in which 10 probe matching trials and 10 probe oddity trials occurred without a supraordinate line tilt on the key. The conditional contingency on such probes, either matching or oddity, was the contingency indicated by the line tilt of the previous trial. Responding on such probes assessed the degree of control by the line-tilt stimuli of the previous trial.

The probe procedure consisted of two trials: Trial A was a regular 0-sec delay trial; on Trial B, no line tilt was present. The basis of correct responding on Trial $B$ was the line tilt from Trial A. An error on an A trial cancelled the B trial, which was then rescheduled for a later time in the session. The pairs of trials for probes for match and oddity were randomly selected from all the possible pairs for each session, counterbalanced for correct side-key position. Therefore, the sample colors of A-B probe trials varied within pairs and among sets of pairs.

To further investigate the trace aspect, both pigeons were then given 65 sessions during which the delay of the supraordi- nate stimulus was gradually increased on 10 match and 10 oddity trials each session. These trials were scheduled as probes. However, in this phase, each correct response to a scheduled B trial increased the delay between line-tilt offset and comparison onset by two observing responses on the next $B$ trial. Each error decreased the delay by two observing responses between termination of the line and termination of the sample color. This was done independently for matching and oddity. An error on the A trial cancelled the B trial, as before. To specify the duration of the elements of the compound sample during the FR 40 observing response, the level was specified as a two value function, e.g., Level $40 / 40$. The first value represented the number of responses during which both supraordinate element and color were present, and the second value represented the number of responses during which only the sample color element was present. At Level 2/40, for example, the supraordinate line tilt was present for two observing responses, and the sample color was present for the FR 40 requirement. Level $2 / 40$ is the last step before Level $0 / 40$ (B-trial of probe), which, as indicated above, is a trial without a supraordinate line tilt.

\section{RESULTS}

Preliminary training was completed in 37 sessions. Acquisition of the red-green, blue-yellow oddity was completed in 31 and 33 sessions for Subjects 35 and 36 , respectively. When matching trials were intermixed with oddity, the subjects developed a complete position preference on both match and oddity trials. Gradually, after 228 and 216 sessions for Subjects 35 and 36 , respectively, criterion performance was reached on intermixed stimuli. Thus, acquisition of supraordinate stimulus control by line tilt was achieved at a 0 -sec delay.

When between-trial probes were first introduced, Pigeon 36 performed on a random basis on trials without a line tilt. By the 11th session, however, a position preference to the left developed. During the last five sessions of this phase, $86 \%$ of all responses on probes were to the left side-key. This indicated that trace control did not extend from one trial to another. However, accuracy on the other 100 trials was not disrupted (85\% correct or more). The absence of a line tilt on the sample came to control a specific response class-left side-key response for this pigeon.

Figure 1 presents the FR value required during the line tilt for matching and oddity on B trials over the 65 sessions during which the delay between line-tilt termination and comparison presentation was modified. As FR value decreased, the delay between the termination of the line tilt and the presentation of the side-key comparison increased. Each decrement in Figure 1 indicates the reduction of the FR value for the line tilt subsequent to a correct response on a B trial. Each increment reflected the increase of the FR value of the line tilt due to an error on a B trial (backup).

Pigeon 35 initially performed better on match trials than on oddity. Within 80 trials, this subject per- 

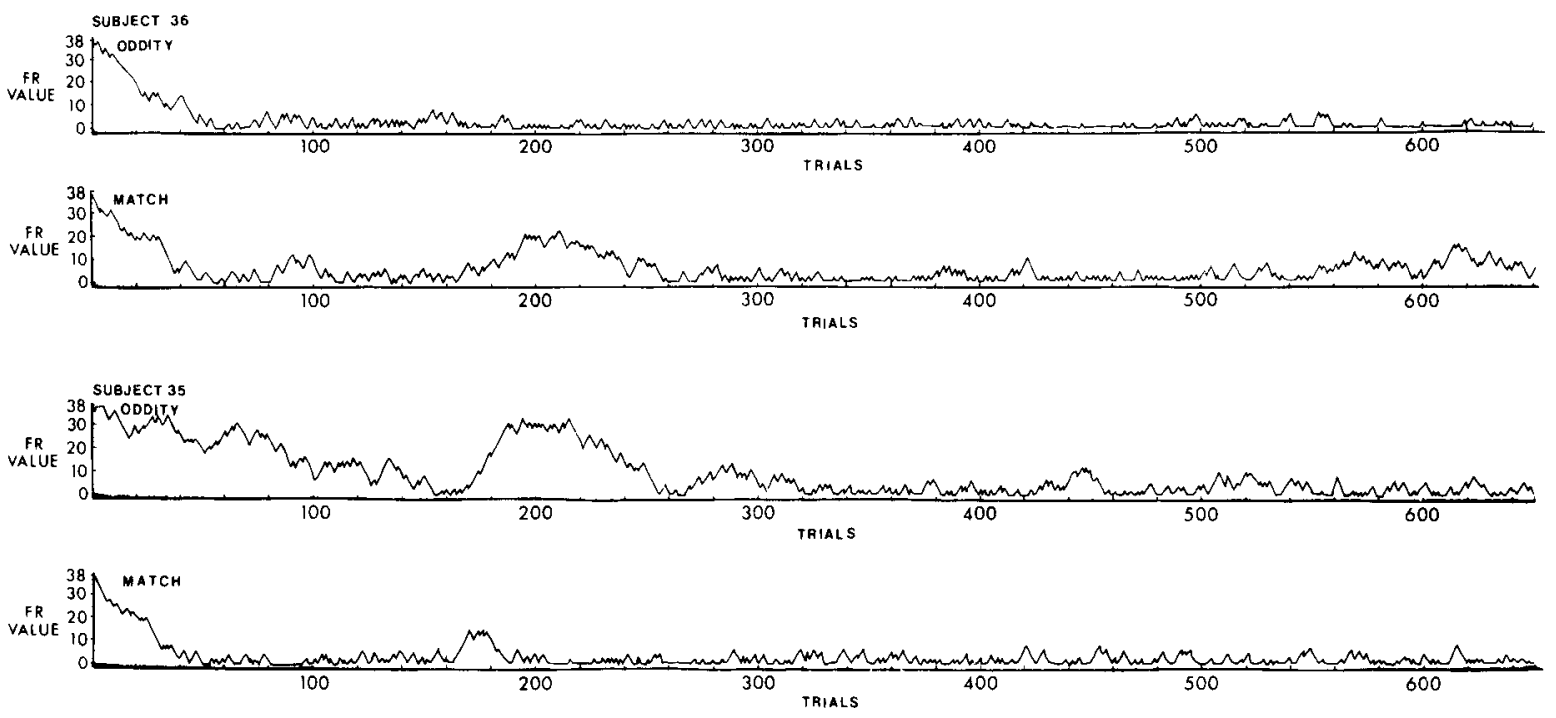

Figure 1. Performance on the titration probe procedure is indicated by FR value of supraordinate line tilt. Each decrease in FR indicates a correct response to a probe. Each increase indicates an error. Matching and oddity are indicated independently.

formed with high accuracy at Level $0 / 40$ on matchto-sample B probes. Oddity performance gradually improved. During the 16th session, the subject was performing at the $0 / 40$ level for matching and oddity. However, there was a subsequent disruption of performance for both types of trials in the following session. Matching performance was disrupted for six sessions, and was accompanied by wingflapping, cooing, and ratio strain during the observing response requirement. Performance on the standard nonprobe trials remained accurate and stable ( $85 \%$ or above correct) for both match-to-sample and oddity-from-sample.

Initially, Pigeon 36 performed accurately on both match and oddity B trials and reached Level $0 / 40$ on both matching and oddity by the sixth session. This pigeon remained at or near Level $0 / 40$ for the entire 65 sessions except for one disruption. This disruption occurred for match trials only, lasted for five sessions, and was concurrent with adjunctive behavior similar to Pigeon 35. The pigeons began the 65 titration sessions 2 weeks apart. Trace control extending from one trial to another, Level $0 / 40$, was attained more often for oddity trials than for match trials.

Figure 2 presents the percent correct for titration trials from Level $8 / 40$ to Level $0 / 40$. Values above Level $8 / 40$ had too few trials to warrant computation of percentage correct. The binomial probability of these percentages occurring by chance is $<.05$ for all values except Pigeon 35 oddity at Level $8 / 40$, which is $<.10$. These results indicate that the titration procedure produced trace supraordinate control which extended from one trial to another (i.e., between-trial control). During the last five sessions, the average time to complete the FR component was 22.5 and $11.7 \mathrm{sec}$ for Pigeons 35 and 36 , respectively. The average latency was .93 and $1.2 \mathrm{sec}$ for Pigeons 35 and 36, respectively.

\section{DISCUSSION}

During the 0-sec-delay task, subjects accurately chose comparison stimuli that were either the same

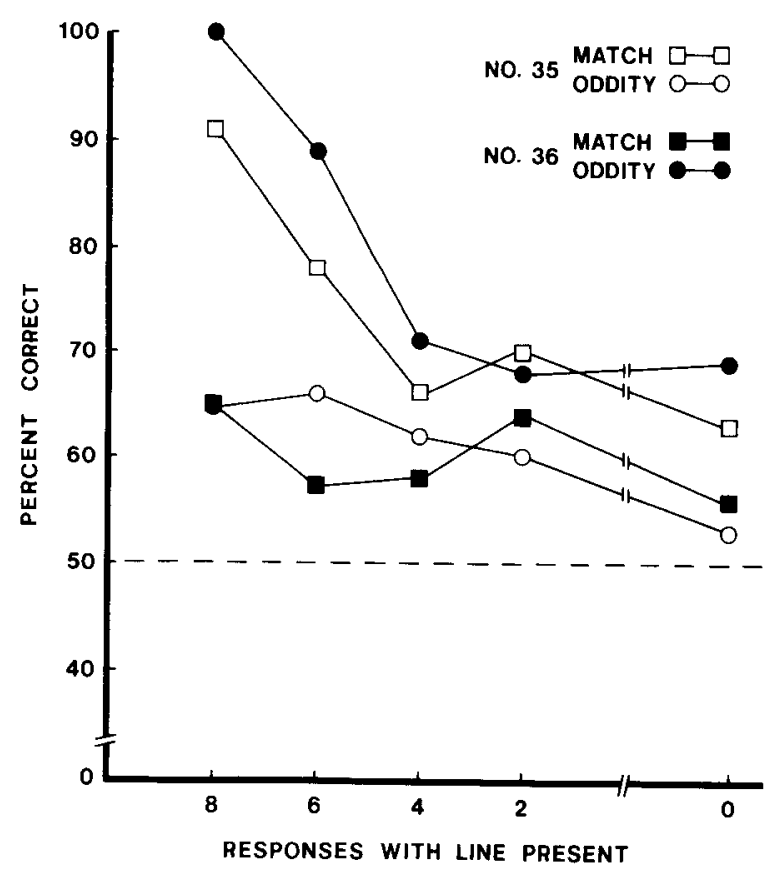

Figure 2. Percent correct for match and oddity trials for Levels $8 / 40$ to $0 / 40$ for both subjects. The probability of these values occurring by chance was $<.05$ except for Pigeon 35 Level $8 / 40$ on oddity, which was $<.10$. The abscissa is broken at 0 responses with line present to indicate trace control between trials. 
as or different from the sample dependent on the line tilt that had been superimposed on the sample hue. Therefore, supraordinate stimulus control was demonstrated. Since neither the sample hue nor line tilt was present during the choice of comparison stimuli, the line tilt, by definition, had supraordinate control over a 0 -sec trace interval within a trial.

The abrupt introduction of probe trials (Level $0 / 40$ ) assessed the extent of the trace control between trials. Although accuracy at Level $40 / 40$ match-tosample and oddity-from-sample was maintained, at Level $0 / 40$ the pigeon did not respond to probes as on the previous trial; the probes controlled a positional response. The supraordinate control of the line tilt, then, did not extend between trials when abruptly introduced.

When titration was introduced, both pigeons displayed control by a supraordinate stimulus that was increasingly separated from the comparison stimuli within a trial. The gradual increase in delay resulted in the extension of control exerted by the supraordinate stimulus within a trial. Further, when probe trials were introduced (Level $0 / 40$ ), better than chance performance occurred, demonstrating that trace control extended between trials. The minimum temporal duration of the delay from offset of the sample on one trial to the onset of the comparison stimuli of the next trial was $10.0 \mathrm{sec}$.

There are a number of reasons for the difficulty of between-trial, trace, supraordinate stimulus control with a 10.0-sec or longer retention interval. Maki and Leith's (1973) data on shared attention with compound samples led to the expectation that acquisition would be slow. Furthermore, Grant and Roberts (1976) and Maki, Moe, and Bierler (1977) have demonstrated the powerful interference effects of illumination during the delay of comparison stimuli in the standard delay match-to-sample procedure. Between-trial trace supraordinate control (Level 0/40) could have been interfered with by the illumination of the side keys, the illumination of the food hopper, the dark intertrial interval, the illumination of the B trial's sample, and finally, by the illumination of the comparison stimuli. Further, only one element of the compound sample of the $A$ trial was relevant for trace control. Indeed, while the line-tilt element was to be remembered, control by the sample color from the A trial would produce further direct interference. These factors may explain the difficulty of the task and the facilitation by the within-trial titration procedure.

The control by discriminative stimuli not present at the time of responding is critical to our understanding of higher order stimulus control, instructional control (Schoenfeld \& Cumming, 1963) and our understanding of "memory." New procedures such as the delayed pair comparison procedure (Shimp \& Moffitt, 1977) and the present procedure are designed to investigate these realms. In addition, the present procedure examined supraordinate control over conditional discriminations. Each new operational unit of analysis of this type of control furthers Salzinger's (1973) contention that the behavior domains, traditionally considered only within a cognitive framework, such as memory, are well within the scope of an experimental analysis.

\section{REFERENCES}

Blovgr, D. S. Delayed matching in the pigeon. Journal of the Experimental Analysis of Behavior, 1959, 2, 151-160.

Cumming, W., \& Berryman, R. Some data on matching behavior in the pigeon. Journal of the Experimental Analysis of Behavior, 1961, 4, 281-284.

Grant, D. S., \& Roberts, W. A. Sources of retroactive inhibition in pigeon short-term memory. Journal of Experimental Psychology: Animal Behavior Processes, 1976, 2, 1-16.

MAKI, W. S., JR., \& LeITH, C. R. Shared attention in pigeons. Journal of the Experimental Analysis of Behavior, 1973, 19, 345-349.

Maki, W. S., Jr., Moe, J. C., \& Bierley, C. M. Short term memory for stimuli, responses and reinforcers. Journal of Experimental Psychology: Animal Behavior Processes, 1977, 3, 156-177.

Nevin, J. A., \& LiE boLd, K. Stimulus control of matching and oddity in a pigeon. Psychonomic Science, 1966, 5, 351-352.

Nevin, J. A. Stimulus control. In J. A. Nevin (Ed.), The study of behavior: Learning, motivation, emotion and instinct. Glenview, Ill: Scott, Foresman, 1973.

REynOLDs, G. A primer of operant conditioning. Glenview, Ill: Scott, Foresman, 1968.

Salzinger, K. Inside the black box with apologies to Pandora: A review of Ulric Neisser's cognitive psychology. Journal of the Experimental Analysis of Behavior, 1973, 19, 369-378.

Schoenfeld, W. N., \& Cumming, W. W. Behavior and perception, in S. Koch (Ed.), Psychology: A study of science (Vol. 5). New York: McGraw-Hill, 1963.

Shimp, C., \& Moffitt, M. Short term memory in the pigeon: Delayed pair comparison procedures and some results. Journal of the Experimental Analysis of Behavior, 1977, 28, 13-25.

(Received for publication January 26, 1978; revision accepted April 19, 1979.) 